\title{
Autoria coletiva e gêneros literários: as concepções filosóficas de Sócrates analisadas pelo viés da crítica textual
}

DOI: http://dx.doi.org/10.21165/el.v50i2.3051

\section{Marcelo Módolo'}

\section{Resumo}

Por meio de instrumental da crítica textual - mormente Cambraia (2005) e Spina (1994) - pretendemos discutir o conceito de autoria em relação ao filósofo ateniense Sócrates. Creditado como um dos fundadores da filosofia ocidental, sua obra é conhecida principalmente por meio de relatos em obras de escritores que com ele conviveram, especialmente dois de seus alunos, Platão e Xenofonte, bem como pelas peças teatrais de seu contemporâneo Aristófanes. Embora na crítica textual esses temas sejam tratados pela questão de fontes ou transmissão indireta, nesse caso tomam um outro contorno: os gêneros (literários) da Antiguidade. Cada gênero seria responsável por moldar uma autoria distinta para Sócrates, obedecendo a seus critérios de verossimilhança exigidos.

Palavras-chave: Sócrates; autoria; gêneros literários; crítica textual.

1 Universidade de São Paulo (USP), São Paulo, São Paulo, Brasil; modolo@usp.br; https://orcid.org/0000-0001-5808-9368 


\title{
Collective authorship and literary genres: Socrates' philosophical conceptions analyzed from the perspective of textual criticism
}

\begin{abstract}
This paper discusses the concept of authorship as it relates to Athenian philosopher Socrates from the viewpoint of textual criticism (see esp. Cambraia 2005 and Spina 1994). Although Socrates is renowned as one of the founding fathers of Western philosophy, his work is fundamentally known through reports of those who knew him, especially two of his students, Plato and Xenophon, and contemporary playwright Aristophanes. Textual criticism would usually deal with this situation by resorting to the methods of source criticism as it applies to indirect transmission. This paper, however, tackles the issue through a discussion of literary genres in Antiquity. It is argued that each genre fashions a different authorial persona for Socrates, following the genre's requirements of verisimilitude.
\end{abstract}

Keywords: Socrates; authorship; literary genres; textual criticism.

\section{Introdução}

Neste baralho de cartas desconexas, dispomos assim de pelo menos quatro trunfos (Platão, Xenofonte, Aristófanes, Aristóteles). Mas é necessário ter presente um princípio: os discursos socráticos são um género literário. São peças sabiamente escritas, por vezes mais de dez anos depois da morte de Sócrates, segundo as convenções do género e as intenções de cada um, e nunca "estenografias em directo", nem sequer crónicas.

(WOLFF, 1987, p. 120)

De determinado ponto de vista, Sócrates pode ser considerado uma personagem quase mitológica, e sua múltipla autoria - entendida como qualidade ou condição de autor, como rezam os dicionários -, reconstituída basicamente a partir de três gêneros literários da Antiguidade: comédia, diálogos (filosóficos) e historiografia. De fato, o que conhecemos da sua vida e da sua contribuição para a Filosofia foi reconstruído em exclusivo graças às obras de outros autores, já que, de acordo com sua ideia de procura contínua e incessante, optou expressamente por uma filosofia oral, com o propósito - ao que nos parece - de fugir do "perigo" que acarretaria fixar em um texto por escrito, de uma vez por todas, os resultados de uma investigação, de uma reflexão ${ }^{2}$. Assim, embora na crítica textual essa condição da transmissão de um "texto" tenda a ser enquadrada nas problemáticas das

2 Alguns comentadores chegam a falar da possibilidade de que Sócrates não sabia ler nem escrever, já que a escrita havia "acabado de chegar" e não estava difundida ou arraigada ainda em Atenas ou na Grécia. 
fontes - como texto do qual se extraem informações ou que serve de base para outras obras - e da tradição indireta, como transmissão de um texto por citações, paráfrases, etc. (vide CAMBRAIA, 2005, e SPINA, 1994), o assunto ganha, nesse caso específico, um contorno peculiar ${ }^{3}$.

Sobre sua vida, temos apenas alguns dados essenciais, obtidos sobretudo a partir dos testemunhos de Aristófanes, Platão e Xenofonte, nos quadros de seus respectivos gêneros literários, haja vista a discordância entre esses autores ser maior que os traços comuns. Outrossim, há outros muitos comentadores menores, que não são levados em conta nesta análise. Segundo o helenista Daniel Rossi Nunes Lopes (comunicação pessoal), a partir da primeira metade do século IV a.C., mais de trezentos diálogos teriam sido escritos sobre a figura de Sócrates. Até os dias atuais, o assunto rende livros e estudos diversos, como Kraus (1967), Stone (2001), Wilson (2013) e até filmes, como o clássico Sócrates (1971) do renomado cineasta neorrealista italiano Roberto Rossellini.

\section{A autoria coletiva das concepções filosóficas socráticas: Aristófanes, Platão e Xenofonte}

Entende-se por autoria, já indicamos, a qualidade ou a condição de autor. É, portanto, atualmente, atributo que resulta do fato de uma pessoa ter feito determinada obra. A autoria, a seu turno, é parte integrante desta, sendo um dos seus elementos constitutivos, pois ela recebe em grande parte as características do escritor que a fez, e isto, mais do que outra coisa qualquer, a distingue das demais, marcando a sua individualidade própria; a obra é um repositório de intencionalidades e depositária de uma agência (GELL, 1998); vide, sobre o tema, ainda as discussões riquíssimas de Agamben (2007), Barthes (2004), Chartier (2014), Gumbrecht (1998) e Hansen e Moreira (2013).

Mas, como qualificar pelo viés da crítica textual a autoria de quem não deixou nenhum escrito? No caso específico, há, no máximo, ideias que, retrabalhadas por outros autores, acabaram por formar um corpus filosófico bastante diverso. Segundo a visão preceptoral de Candido $(2005)^{4}$, durante muito tempo - dos fins do século XVIII até a atualidade - deu-se grande importância a teorias que falavam da criação coletiva, apresentando o povo como criador anônimo de obras orais. Devemos aí distinguir a literatura oral popular da literatura erudita. A primeira exprime estados de espírito comuns a um grupo; transmite-se por tradição, de boca em boca, e vai sofrendo as alterações a que esse processo está sujeito. Já, se considerarmos as obras eruditas, isto é, por oposição às populares - em oposição que é sempre relativa e intrassistêmica -, as que são escritas e integram a tradição literária, veremos que a autoria é, em muitos contextos, elemento

3 Agradeço a Eduardo Henrik Aubert e a Maria de Fátima Nunes Madeira a leitura deste texto e as pertinentes sugestões que ofereceram para seu aprimoramento.

4 Muito útil, didática, apesar de incorrer em um certo reducionismo. 
indispensável à sua caracterização. Mas aí convém distinguir as obras cujos autores são conhecidos, e, portanto, considerados parte delas, e aquelas cujos autores são ignorados, por um motivo qualquer. De modo geral, à medida que chegamos mais perto do nosso tempo, mais agudo se torna o problema da autoria, mais forte a noção de que é preciso considerar o autor de uma obra, e mais acentuada a reivindicação que ele faz sobre ela. Contribuíram diretamente para isto o desenvolvimento do individualismo e as teorias que dão papel preponderante ao artista no processo criador, bem como o reconhecimento de uma posição e uma função social do escritor. Antes, ele era protegido ou marginal. No mundo moderno, passou a ser um profissional.

No caso de Sócrates, a autoria somente pode ser reconhecida de forma mediata, pelos gêneros literários nos quais ele foi inserido, "criado", por assim dizer. Se há textos sem autores conhecidos, aqui temos autor sem texto conservado, justamente porque não escrito.

Passemos aos três autores supracitados e seus respectivos gêneros, nos quais "Sócrates" é inserido como personagem.

\section{Diferentes Sócrates, a depender de seu gênero literário}

Diante da já assinalada disparidade entre os "Sócrates" que comparecem em Aristófanes, Platão e Xenofonte, durante muito tempo, e até hoje, os historiadores da filosofia se perguntam qual seria o verdadeiro Sócrates ou, ao menos, qual seria aquele mais próximo do Sócrates histórico, vide o trabalho monumental de Magalhães-Vilhena (1984). A pergunta, pensamos, está, se não mal posta, já que é legítimo postular a existência da personagem histórica, certamente formulada de modo a obliterar o relevantíssimo processo efetivamente documentado, que é o da elaboração da autoria de Sócrates na cabeça de uma tradição, vale dizer, o processo de criação do protagonista daquilo que se vai tornando o mito fundador da tradição filosófica. Passemos, agora, a uma análise prévia dos três autores.

\section{Aristófanes}

A comédia de Aristófanes (c.445 a.C. - c.388 a.C) - As nuvens - constitui a fonte mais antiga sobre Sócrates, vide Aristófanes (1980). Nessa obra, escrita aos 22 anos, Aristófanes zomba, com a sua sátira mordaz, tanto do novo rumo político da democracia ateniense como do transformado clima cultural e educativo da cidade. Os protagonistas dessa comédia são Estrepsíades e o seu filho Fidípedes, que, assediados por credores, esperam aprender com Sócrates a arte da capciosidade dialética para conseguirem se defender das acusações. 
Poderíamos extrair dessa comédia de Aristófanes duas informações importantes. Em primeiro lugar, considerações de índole histórica: nos anos 424-423 a.C., Sócrates devia ser já uma figura de destaque em Atenas, para que Aristófanes lhe decidisse atribuir um papel central em sua comédia, apesar de ser um papel humilhante ${ }^{5}$. Em segundo lugar, seria possível extrair alguns pormenores tanto da personalidade de Sócrates como das primeiras fases de sua reflexão filosófica. No texto de Aristófanes, ele já apresenta, mesmo que seja apenas de forma implícita, sua típica maneira de filosofar que voltaremos a encontrar mais adiante nos Diálogos platônicos e que o caracterizam, isto é: fazer perguntas, pôr à prova a fecundidade de seu interlocutor, a utilização da arte de maiêutica (a técnica de fazer aflorar a verdade latente em cada um de nós). Pelo modo como Aristófanes descreve Sócrates, não se pode excluir a possibilidade de que, ao comediógrafo e a seus concidadãos, a atitude socrática lhes parecesse, sobretudo de início, extravagante e excêntrica. Observemos a fala de Fidipedes, segundo Aristófanes (1995, p. 6): "Agora eu sei quem são eles! Você está falando daqueles vigaristas, descalços e brancosos, daquela turma onde estão o maldito Sócrates e o Cairefon maldito.".

No entanto, a principal acusação que Aristófanes lhe lançava era a de ser o pior dos sofistas e de se interessar exclusivamente por elaborar discursos enganosos, conforme a fala de Estrepsíades, segundo, ainda, Aristófanes (1995, p. 6):

O pessoal diz que eles usam dois raciocínios ao mesmo tempo: o justo e o injusto. Um desses raciocínios - o injusto - derrota o outro - o justo - defendendo as causas injustas. Então, se você me der o prazer de aprender esse raciocínio injusto, eu não vou pagar a ninguém um simples centavo de todas as dívidas que eu contraí por sua causa, meu filho.

Que Sócrates esteja, em diversos aspectos, em dívida com a tradição sofística, é inegável, embora, como veremos a seguir, seu grande mérito esteja em ir um passo além, na autoria cunhada por Platão.

Conforme reconhece Victor Coulon (ARISTOPHANE, 2008), Aristófanes está evidentemente detratando Sócrates na peça. No entanto, "a comédia antiga admitia, contra os particulares, ataques que hoje pareceriam terrivelmente difamatórios" (ARISTOPHANE, 2008, p. 152), em que elementos da realidade - certamente algo da aparência de Sócrates, seu envolvimento com práticas discursivas - são tomados como

5 Seria impróprio considerar a questão da "baixeza de estilo" nessa comédia, já que é uma determinação aristotélica e não parecia estar em voga no tempo de Aristófanes. As comédias, tanto quanto as tragédias de então, faziam parte do mesmo ritual ao deus Dionísio. Além disso, as comédias aristofânicas comumente têm personagens importantes, como políticos, de modo a contrastar com a classificação aristotélica. Aristóteles já mira a comédia média, em que se evitava usar personagens reais famosos, justamente para não os constranger. 
elementos de intersecção entre mundo externo e mundo da representação, a que se aplicam as convenções genéricas, como espécies de vetores de adequação do mundo circunstante ao mundo genericamente pré-estruturado da comédia. Como bem nota Humphreys (1913, p. 10), "esses distanciamentos da realidade eram necessários, pois, para o poeta, Sócrates é um conceito de grupo e é satirizado como tal". A própria inclusão de Aristófanes no Banquete de Platão (189a-193d), que, segundo Humphreys, é traço de que a crítica foi entendida em seus pressupostos genéricos, e não como indicativa da apreciação real de Aristófanes sobre Sócrates, é indicativo de que, em uma espécie de processo sistêmico de construção da autoria de Sócrates, sua inclusão na comédia não é indício de elemento destrutivo, ou anticonstrutivo, mas peça articulada e solidária com os demais textos do corpus.

\section{Platão}

De um ponto de vista cronológico, os diálogos de Platão (c. 428-427 a.C. - c. 348-347 a.C.) representam a segunda possibilidade de construção de autoria, após a obra de Aristófanes, que nos faculta informação sobre o processo de construção da autoria de Sócrates, vide, por exemplo, Platão (2011).

Platão, na qualidade de discípulo direto de Sócrates, transforma o mestre no protagonista indiscutível da maioria de seus textos, descrevendo-o como um homem sábio, justo, o melhor dos educadores e um guia moral. Vide uma das inúmeras descrições em Platão (s.d.):

Eis a verdade, cidadãos atenienses, e eu falo sem esconder nem dissimular nada de grande ou de pequeno. Saibam, quantos o queiram, que por isso sou odiado; e que digo a verdade, e que tal é a calúnia contra mim e tais são as causas. E tanto agora como mais tarde ou em qualquer tempo, podereis considerar essas coisas: são como digo.

Quando se avalia a obra platônica é, no entanto, necessário levar em conta o relevante processo de transformação da figura de Sócrates, sejam quais forem as relações entre esse processo e o Sócrates fora do texto; assim, a distinção entre o Sócrates histórico e o Sócrates platônico, cara à tentativa de extrair a verdade da ficção, segundo a velha diretriz de que já se tratou, vai ressignificada como um processo de longa construção da personagem dentro do gênero e, inextricavelmente, de reconfiguração do gênero com o reprocessamento da personagem.

Segundo Bolzani Filho (2014) adaptado, Platão não escreve seus diálogos "socráticos" com o mesmo objetivo de uma tragédia, mas sim para introduzir uma nova forma de pensar, que será chamada, por ele e pela posteridade, de "filosofia". Não se trata simplesmente de exercitar um lógos à maneira tradicional, mas de lançar mão dessa tradição, para veicular 
uma nova visão de mundo. A mímesis, nas mãos de Platão, obedece a interesses próprios de seu autor, que incluem a elaboração de um êthos novo, "filosófico", na figura do mestre. À luz do esquema aristotélico, trata-se de pintar o retrato, não de um Alcibíades, mas de um "protofilósofo", que, também conforme o esquema aristotélico, deve ser visto como universal: é o "ser filósofo" que se expressa nessa verossímil personagem, cujo nome próprio e particular é "Sócrates", e que retoma, para desenvolvê-los, aspectos realmente presentes no Sócrates que viveu em Atenas no século $V$ a.C. Por tudo isso, mais do que a ação, trata-se de destacar o caráter e o pensamento. Talvez se possa então defender que, no caso dos lógoi sokratikoí - ao menos no caso de Platão -, se opere certa inversão: as práxeis, explicáveis em virtude de uma diánoia que aponta para um êthos, são agora uma forma de beneficiar a construção deste último: Platão visa à elaboração do êthos socrático e, para tal, serve-se de uma prâxis e de uma diánoia.

Do ponto de vista da construção da personagem no interior de um gênero - desde que se entenda que o gênero não é fetiche, mas um conjunto de práticas discursivas aptas a se mesclar em todos complexos, multigenéricos - pode-se remeter à história do encontro entre Sólon e Creso nas Histórias de Heródoto (1, 30-33), como espécie de modelo ou manifestação de modelo apto a ser captado por Platão. Heródoto narra como Sólon foi visitar o rico Rei Creso, em Sardis, por quem foi abrigado em seu palácio. Creso Ihe mostra todos os tesouros e lhe pergunta se ele já vira homem ỏ $\lambda \beta \iota \omega ́$ татоৎ, pelo que entende homem mais rico. Sólon responde que sim, citando exemplos de homens que tiveram

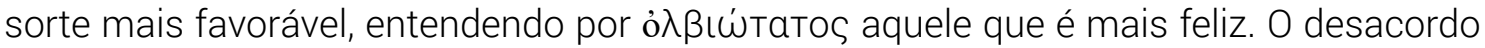
vai se estendendo conforme Creso renova a pergunta, esperando ser sancionado como o ỏ $\lambda \beta \iota \omega ́$ татоs, sempre frustrado, até que, em longo discurso a Creso irritado, Sólon indica que, em todas as coisas, é preciso investigar o fim, pois só as coisas findas poder-se-ia julgar se foram favoráveis ou não. Ao longo do discurso, vai contrapondo à compreensão limitada do conceito de ö $\lambda \beta ı$ ıs subentendida por Creso uma noção mais complexa. O diálogo é afim aos múltiplos passos platônicos em que Sócrates desfaz as preconcepções de seus interlocutores a respeito do sentido de determinadas palavras, impondo-lhes, no próprio intercurso, definição refinada por procedimentos de distinção e de exemplificação. Assim, sem dúvida, há modelos genéricos que respondem, ao menos parcialmente, pela construção da personagem de Sócrates no diálogo filosófico tal qual nos foi legado por Platão.

\section{Xenofonte}

Embora Xenofonte tenha sido um polígrafo, ele passou a ser conhecido como historiador, formando, ao lado de Tucídides e Heródoto, a tríade canônica de historiadores gregos antigos. Modernamente, porém, segundo Cerdas (2016) adaptado, contesta-se muito sua qualidade enquanto historiador e até mesmo a sua integração a esse cânone. Segundo ainda Cerdas (2016), a literatura recente sobre esse autor segue igualmente tendência da segunda metade do século XX de encarar o discurso historiográfico não como um campo isolado, mas um terreno misto entre a literatura e a ciência. 
Conforme Hayden White (1995, p. 17), se no século XIX acreditava-se que a história, ou o conhecimento histórico, era um domínio autônomo, no século XX, pensadores "[...] expressaram sérias dúvidas sobre o valor de uma consciência especificamente "histórica", sublinharam o caráter fictício das reconstruções históricas e contestaram as pretensões da história a um lugar entre as ciências.".

Trabalhos como o de Roland Barthes (2004b), questionando a construção do discurso historiográfico, pensam a obra do historiador como um discurso que, como tal, se estabelece por meio de uma série de dispositivos linguísticos e estruturais, que tornam a obra pertencente a um gênero, o historiográfico, e que, portanto, é passível de ser reconhecido pelos seus leitores. O gênero historiográfico, então, é a manifestação do uso de categorias discursivas - que se assemelham às do discurso literário - na organização e apresentação do fenômeno histórico, o que implicitamente indica, segundo White (2009), a ficcionalização dos dados históricos. O conceito de ficcionalização usado por White não se refere à narrativa cuja matéria é inventada, mas sim ao uso de uma determinada organização dos dados históricos a fim de se criar um enredo que é, como narrativa, semelhante ao tipo de organização da ficção, por exemplo, a dos romancistas. A própria construção do "efeito de real" que se dá na transposição do acontecimento histórico em escrita é, conforme Barthes (2004b), o mesmo recurso usado por Flaubert, na tentativa de apagar o enunciador para criar a impressão de que os eventos ocorreram tal qual são narrados, sem a organização de um autor por trás da narrativa.

Dito isso, é de se destacar a obra mais importante de Xenofonte, Memoráveis, ou ditos e feitos memoráveis de Sócrates, composta por quatro livros que narram as vivências do filósofo, vide Xenofonte (1980). Destaca-se, ainda, que Xenofonte é também autor de uma segunda Apologia de Sócrates, que funciona como uma espécie de contrapeso da homônima platônica, e de alguns escritos tidos como menores, como o Econômico ou o Banquete.

Para avaliar esses relatos, seria preciso levar em conta uma série de considerações além das palavras iniciais desse subcapítulo. Antes de mais nada, destacaríamos que Xenofonte foi, em sua juventude, testemunha direta da predicação socrática, enquanto as Memoráveis remontam à maturidade do autor: encontramo-nos, assim, perante um significativo lapso temporal que, provavelmente, influiu na sua reconstrução da atividade de Sócrates. As opiniões sobre a obra de Xenofonte atravessaram fases mutáveis no decurso dos séculos. Enquanto filósofos como Hegel e Nietzsche exaltaram seu valor e destacaram a fidelidade (em sua opinião, inclusive superior à platônica) com a qual o historiador teria descrito a figura de Sócrates, outros, como Bertrand Russel, questionaram severamente a capacidade de Xenofonte reproduzir, de maneira adequada, a contribuição de Sócrates, precisamente em razão de sua falta de formação filosófica. Para observar pormenorizadamente essas questões, vide Bermudo (2015). 
Porém, segundo Dorion (2006), tudo leva a crer que nem Xenofonte nem Platão conceberam o projeto de expor fielmente o pensamento de Sócrates. Os escritos socráticos desses autores resultam de um gênero literário, o logos sokratikos, que é explicitamente reconhecido por Aristóteles e que autoriza, em virtude de sua natureza, uma grande liberdade de invenção, tanto no que se refere à encenação como quanto ao conteúdo, a saber, as ideias expressas pelas diferentes personagens.

\section{Conclusões}

Evidentemente, o reconhecimento de que o Sócrates de que dispomos é um emaranhado de discursos concatenados em um processo de estabelecimento de uma persona autoral que carrega aquele nome não esvazia, já alertamos, a reflexão sobre a existência de um Sócrates histórico.

Afınal, o processo de construção de autoria é solidário com a existência daquela personagem, com cuja experiência de vida se vai entretecendo sem solução de continuidade; os textos de que dispomos vão certamente reverberando realidades intersubjetivas em que Sócrates participou, em vida e na projeção das intencionalidades infundidas em suas palavras que ganhavam objetividade no processo social de sua rememoração e reelaboração.

Vimos que o pensamento de Sócrates foi reinterpretado muitas vezes, inclusive em tempos recentes, a partir de diferentes perspectivas, até mesmo opostas. Portanto, a pergunta que, neste ponto, poderíamos fazer é a seguinte: apesar das várias possibilidades de leitura, também por causa da falta de fontes diretas, o que mais profundamente caracteriza o pensamento socrático é o que pode continuar a nos servir de inspiração, principalmente em relação ao método maiêutico.

Na crítica textual, a questão da autoria é tratada sob as perspectivas, seja das fontes, seja da tradição indireta. O tema deve ser mais comum em estudos sobre edição de textos clássicos, já que em textos medievais e modernos parece ser uma questão mais rara. No entanto, no caso socrático é algo mais complexo do que a mera tradição indireta, pois Platão provavelmente não terá escrito seu trabalho a partir de textos escritos de Sócrates, mas sim de sua memória em relação ao que este disse, uma vez que a tradição oral era a norma na Antiguidade.

Se uma mesma obra (ou temática) de Sócrates foi transmitida por mais de um comentador, haveria espaço para uma colação ${ }^{6}$ para se discutir o grau de diferenciação

6 Colação: comparação (collatio codicum) de todos os testemunhos de um texto para reconhecer todas as suas variantes. Operação necessária para a constituição do processo genético (para os testemunhos autógrafos) ou do estema (para as tradições), ou para a organização dos cadernos na bibliografia material. 
que esse tipo de transmissão propicia. Portanto, é para ser fiel à nossa convicção de que a questão socrática não pode ser resolvida, mas também pela preocupação de ilustrar a diversidade das representações de Sócrates que já se encontra em seus testemunhos imediatos, que optamos por apresentar, em nome e em lugar de um inapreensível, mas talvez vislumbrável, Sócrates histórico, os diferentes retratos de Sócrates esboçados por nossas principais fontes: Aristófanes, Platão, Xenofonte.

Os gêneros não são a concretização artística de uma essência "natural" e inerente a eles, mas são sistemas abertos, sujeitos às misturas, mudanças e reformulações de acordo com as necessidades de diferentes contextos culturais e sociais. Isso significa que, se os gêneros não têm uma natureza, eles têm uma história (WHITE, 2009), que vai se construindo à medida que é atualizado e reatualizado pela própria experiência dos escritores. Deste modo, assim se constroem a multiplicidade "dos Sócrates" que encontramos na literatura aqui brevemente exposta.

\section{Agradecimentos}

O presente trabalho foi realizado com apoio de bolsa de produtividade em pesquisa do CNPq - nível 2 (processo número 308793/2019-6) concedida ao autor.

\section{REFERÊNCIAS}

AGAMBEN, G. O autor como gesto. In: AGAMBEN, G. Profanações. Tradução Selvino José Assmann. São Paulo: Boitempo, 2007. p. 55-63.

ARISTÓFANES. As nuvens. Seleção de textos de José Américo Motta Pessanha, tradução de Gilda Maria Reale Starzynski. 2. ed. Coleção Pensadores. São Paulo: Abril Cultural, 1980.

ARISTÓFANES. As nuvens. Tradução Mário da Gama Kury. 1995. Disponível em: https:// bit.ly/3kylwt3. Acesso em: 02 jun. 2021.

ARISTOPHANE. Comédies: tome I, les Acharniens, les Cavaliers, les Nuées. Ed. Victor Coulon. Tradução Hilaire van Daele. Paris: Les Belles Lettres, 2008 [1923].

BARTHES, R. A morte do autor. In: BARTHES, R. Rumor da língua. São Paulo: Martins Fontes, 2004a. p. 57-64.

BARTHES, R. O discurso da história. In: BARTHES, R. Rumor da língua. São Paulo: Martins Fontes, 2004b. p. 163-190. 
BERMUDO, J. M. Sócrates: mestre da filosofia e da vida. São Paulo: Salvat, 2015.

BOLZANI FILHO, R. Imagens de Sócrates. Kl é o s, n. 18, p. 11-31, 2014.

CAMBRAIA, C. N. Introdução à crítica textual. São Paulo: Martins Fontes, 2005.

CANDIDO, A. Noções de análise histórico-literária. São Paulo: Associação Editorial Humanitas, 2005.

CERDAS, E. A história segundo Xenofonte: historiografia e usos do passado. 2016. Tese (Doutorado em Estudos Literários) - Faculdade de Ciências e Letrasm Universidade Estadual Paulista "Júlio de Mesquita Filho", Araraquara, 2016. Disponível em: https://bit. ly/2luJ3hD. Acesso em: 02 jun. 2021.

CHARTIER, R. O que é um autor? Revisão de uma genealogia. Tradução Luzmara Curcino e Carlos Eduardo de Oliveira Bezerra. São Carlos: EdUFSCar, 2014.

DORION, L. A. Compreender Sócrates. São Paulo: Vozes, 2006.

GELL, A. Art and agency: an anthropological theory. Oxford: Clarendon Press, 1998.

GUMBRECHT, H. U. O autor como máscara. In: GUMBRECHT, H. U. Modernização dos sentidos. Tradução Lawrence Flores Pereira. São Paulo: Ed. 34, 1998. p. 97-108.

KRAUS, R. Sócrates: sua vida pública e privada. Tradução Marina Guaspari. Coleção Vidas Extraordinárias. Rio de Janeiro: Casa Editora Vecchi, 1967.

HANSEN, J. A.; MOREIRA, M. Para que todos entendais: poesia atribuída a Gregório de Matos e Guerra. Apresentação, edição, notas e glossário João Adolfo Hansen e Marcello Moreira. v. 5. Belo Horizonte: Autêntica, 2013.

HUMPREYS, M. W. Aristophanes'Clouds. Boston: Ginn and Company, 1913.

MAGALHÃES-VILHENA, V. O problema de Sócrates: o Sócrates histórico e o Sócrates de Platão. Lisboa: Calouste Gulbenkian, 1984.

PLATÃO. Apologia de Sócrates. Êutifron. Críton. Introdução, tradução do grego e notas de André Malta. Porto Alegre: L\&PM, 2011. 
PLATÃO. Apologia de Sócrates. Tradução Maria Lacerda de Souza. (s.d.). Disponível em: https://bit.ly/3wRwRe7. Acesso em: 02 jun. 2021.

ROSSELLINI, R. Sócrates. 1971. Disponível em: https://bit.ly/2IEQz9c. Acesso em: 02 jun. 2021.

SPINA, S. Introdução à edótica: crítica textual. 2. ed. revista e atualizada. São Paulo: Ars Poética: Editora da Universidade de São Paulo, 1994.

STONE, I. F. O julgamento de Sócrates. São Paulo: Companhia das Letras, 2001.

XENOFONTE. Ditos e feitos memoráveis de Sócrates. Apologia de Sócrates. Seleção de textos de José Américo Motta Pessanha, tradução Líbero Rangel de Andrade, por meio da versão francesa de Eugène Talbot. 2. ed. Coleção Pensadores. São Paulo: Abril Cultural, 1980.

WHITE, H. "Reflections of "gendre" in the discourses of history". New literary history, v. 40, n. 4, p. 867-877, 2009.

WHITE, H. Meta-história: a imaginação histórica do século XIX. Tradução José Laurencio de Melo. São Paulo: EDUSP, 1995.

WILSON, E. A morte de Sócrates. Tradução Maria de Fátima Siqueira de Madureira Marques. Revisão técnica de Flávia Schlee Eyler. Rio de Janeiro: Record, 2013.

WOLFF, F. Sócrates. Coleção Estudos Gerais. Tradução Manuela Torres. Lisboa: Teorema, 1987. 